\title{
Inhibitory mechanism of muscone in liver cancer involves the induction of apoptosis and autophagy
}

\author{
WENCHUAN QI ${ }^{1}$, ZHENHUA LI $^{2}$, CHUNLAN YANG $^{1}$, JIANGSHAN DAI $^{1}$, QIAO ZHANG ${ }^{3}$, \\ DI WANG ${ }^{1}$, CHUANFANG WU $^{1}$, LONGJIANG XIA ${ }^{4}$ and SI XU ${ }^{1,5}$
}

\begin{abstract}
${ }^{1}$ Key Laboratory of Bio-Resource and Eco-Environment of The Ministry of Education, College of Life Sciences, Sichuan University, Chengdu, Sichuan $610065 ;{ }^{2}$ Department of Orthopedics, Changchun University of Traditional Chinese Medicine; ${ }^{3}$ Department of Orthopedics, China-Japan Friendship Hospital Affiliated Jilin University, Changchun, Jilin 130021; ${ }^{4}$ College of Basic Medicine, Chengdu University of Traditional Chinese Medicine, Chengdu, Sichuan 611137; ${ }^{5}$ College of Physical Education, Sichuan Normal University, Chengdu, Sichuan 610072, P.R. China
\end{abstract}

Received September 18, 2019; Accepted January 10, 2020

DOI: $10.3892 / o r .2020 .7484$

\begin{abstract}
Traditionally, musk has been used as an analgesic to treat pain associated with cancer. Hepatocellular carcinoma (HCC) is an aggressive tumor; however, patients with liver cancer that received musk were reported to live longer and have a higher quality of life. Thus, the present study aimed to investigate whether muscone, a macrocyclic compound of musk, demonstrated potential as an anti-liver cancer drug for the non-surgical treatment of advanced liver cancer. Briefly, liver cancer cells were treated with muscone and the rates of cellular apoptosis and autophagy were investigated using staining techniques and western blotting. The underlying molecular mechanisms of muscone were evaluated using high-throughput sequencing and the in vitro effects of muscone were subsequently validated in vivo using a nude mouse model. Muscone increased the rates of apoptosis and autophagy in liver cancer cells; the increase in cellular apoptosis was observed to occur through endoplasmic reticulum stress responses, whereas muscone-induced autophagy was closely associated with the AMP kinase/mTOR complex 1 signaling pathway. These findings were verified in vivo. Notably, sestrin-2 expression levels were also significantly decreased in liver cancer tissues compared with paracancerous tissues. In conclusion, the present study
\end{abstract}

Correspondence to: Professor $\mathrm{Si} \mathrm{Xu}$, College of Physical Education, Sichuan Normal University, Section 2, 1819 Chenglong Avenue, Longquan, Chengdu, Sichuan 610072, P.R. China

E-mail: bearpp@126.com

Professor Longjiang Xia, College of Basic Medicine, Chengdu University of Traditional Chinese Medicine, 37 Shi'er Qiao Road, Chengdu, Sichuan 611137, P.R. China

E-mail: xialongjiang@126.com

Key words: hepatocellular carcinoma, muscone, endoplasmic reticulum stress, sestrin 2/AMP kinase/mTOR pathway, apoptosis, autophagy suggests that muscone demonstrates potential as an anticancer drug, and the findings of the present study provide the basis for the development of effective anticancer drugs derived from natural compounds.

\section{Introduction}

Hepatocellular carcinoma (HCC) is the fifth most common malignant tumor worldwide and the third most common cause of cancer-related death (1). Unfortunately, HCC tumors are aggressive, difficult to detect and exhibit a complex pathology, which makes them highly refractory in nature. While less than $30 \%$ of patients with HCC are suitable for resection and orthotopic liver transplantation, which is commonly accepted as the most effective treatment (2), advanced HCC cases lack adequate therapeutic treatments. Moreover, high rates of metastasis and relapse limit the long-term efficacy of surgery (3) and HCC frequently demonstrates resistance to systemic chemotherapy, with the National Comprehensive Cancer Network guidelines recommending that chemotherapeutics are not prescribed for the treatment of HCC in clinical practice (4). Although sorafenib has demonstrated potential as a drug for advanced liver cancer in the SHARP and START (5-7) studies, its application in advanced $\mathrm{HCC}$ is limited by poor responses and various side effects (8). Similarly, radiotherapy in HCC is also limited due to the radiation dosage and tumor positioning (9-11). Currently, the most commonly used non-surgical therapies for liver cancer are transarterial chemoembolization and transarterial embolization. Both treatments significantly improve the prognosis of patients with multiple lesions and a large tumor mass whose livers are not tolerant to surgery $(12,13)$; however, they are often associated with incomplete embolization, the formation of collateral circulation and liver function damage following repeated procedures (14). Additionally, they do not effectively control distant metastasis rates. Thus, there is unanimous agreement for the urgent requirement to develop novel, more effective drugs and treatment methods for the clinical treatment of HCC $(5,15)$. One suggested approach is to identify drugs that are derived from natural compounds with anticancer activity. 
Musk and its preparations have been used as traditional analgesics for treating pain resulting from various types of cancer, including liver cancer (16); it is particularly popular among the Tibetans in Sichuan, China, which due to their health philosophy, receive no surgical intervention or non-surgical treatments. Over the past decade, follow-up studies in dozens of patients with advanced liver cancer from the Tibetan region observed that the use of musk as an analgesic increased their quality of life and lifespan, suggesting that the ingredients within musk may inhibit liver cancer progression in addition to their analgesic properties.

Since these observations, modern basic and clinical pharmacological studies have confirmed that musk and its preparations are effective in the treatment of central nervous system and cardiovascular/cerebrovascular diseases, as demonstrated in a previous study of the Shexiang Baoxin pill (17). Previous studies have investigated the antitumor properties of musk, including Shengjizonglu and TaipingHuiminHejijuFang (18), and musk and muscone were found to inhibit cell growth in Ehrlich ascites carcinoma, sarcoma -180 and HCC (19). Clinical studies have also reported that musk-containing compound drugs, such as Xihuangwan, Xiaojindan, and Liushenwan demonstrated certain anticancer effects (20). The active anticancer ingredients of musk are thought to include the macrocyclic ketones, of which 3-methylcyclohexanone (muscone) is the major one (21), and synthetic dextral muscone has demonstrated activities similar to natural sinistral muscone (22). However, the antitumor mechanisms of musk/muscone in liver cancer are unclear.

Based on the clinical observations that have suggested that muscone exhibits anticancer properties, the present study aimed to investigate whether it could be used as an anti-liver cancer drug for the non-surgical treatment of advanced liver cancer. The inhibitory effects of synthetic muscone were tested on various liver cancer cell lines, and its target sites and mechanisms of action were also explored. In addition, the in vitro findings were validated in vivo, in nude mice with transplanted tumors, as well as in clinical HCC specimens.

\section{Materials and methods}

Reagents and antibodies. Muscone was obtained from Chengdu Kangfei Co., Ltd. and was dissolved in DMSO (Amresco, LLC); and 4-phenylbutyrate (4-PBA) was purchased from Sigma-Aldrich; Merck KGaA. Primary antibodies against phosphorylated (p)-protein kinase R-like endoplasmic reticulum kinase (PERK) (dilution 1:1,000; cat. no. SAB4301310), p-eukaryotic initiation factor (eIF) $2 \alpha$ (dilution 1:1,000; cat. no. SAB4504388), p-AMP kinase (p-AMPK) (dilution 1:1,000; cat. no. SAB4503754) and p-mTOR (dilution 1:1,000; cat. no. SAB4504282) were purchased from Sigma-Aldrich; Merck KGaA; the primary antibody against light chain 3B (LC3B; dilution 1:1,000; cat. no. 2775) was purchased from Cell Signaling Technology, Inc.; antibodies against Bcl-2 (dilution 1:500; cat. no. sc-7382), pro caspase-3 (dilution 1:500; cat. no. sc-7272), AMPK (dilution 1:500; cat. no. sc-74461), Bax (dilution 1:500; cat. no. sc-7480) and mTOR (dilution 1:500; cat. no. sc-517464) were purchased from Santa Cruz Biotechnology, Inc.; anti-3-methyladenine (3-MA) primary antibodies were purchased from Selleck Chemicals; the anti-activating transcription factor (ATF)4 (dilution 1:500; cat. no. AF2560) and anti-DNA damage inducible transcript (DDIT) 3 (dilution 1:500; cat. no. AF6684) antibodies were purchased from Beyotime Institute of Biotechnology; and the cleaved caspase-3 (dilution 1:1,000; cat. no. 19677-1-AP), anti-sestrin (SESN)2 (dilution 1:1,000; cat. no. 10795-1-AP), anti- $\beta$-actin primary antibodies (dilution 1:5,000; cat. no. 66009-1-Ig), horseradish peroxidase (HRP)-conjugated secondary antibodies including HRP-conjugated Affinipure goat anti-mouse $\operatorname{IgG}(\mathrm{H}+\mathrm{L})$ (dilution 1:10,000; cat. no. SA00001-1), HRP-conjugated Affinipure goat anti-rabbit $\operatorname{IgG}(\mathrm{H}+\mathrm{L})$ (dilution 1:10,000; cat. no. SA00001-2) and HRP-conjugated Affinipure rabbit anti-goat $\operatorname{IgG}(\mathrm{H}+\mathrm{L})$ (dilution 1:10,000; cat. no. SA00001-4) were purchased from ProteinTech Group, Inc.

Cell culture and small interfering RNA (siRNA) transfection. Human hepatoma/liver cancer HepG2 cells, Hep3B cells, human lung carcinoma A549 cells and human colorectal cancer HCT116 cells were purchased from The Cell Bank of the Type Culture Collection of the Chinese Academy of Sciences and were validated using short tandem repeat DNA profiling. HepG2, Hep3B and A549 cells were cultured in RPMI-1640 medium (Logan), and HCT116 cells were cultured in DMEM (Logan). Both media were supplemented with $100 \mathrm{U} / \mathrm{ml}$ penicillin, $100 \mu \mathrm{g} / \mathrm{ml}$ streptomycin and $10 \%$ FBS (Gibco; Thermo Fisher Scientific, Inc.) and cells were cultured in a humidified atmosphere at $37^{\circ} \mathrm{C}$ in $5 \% \mathrm{CO}_{2}$.

siRNA against SENS2 (5'-GACCAUGGCUACUCGCUG ATT-3') and the negative control (NC; 5'-UUCUCCGAACGU GUCACGUTT-3') were purchased from Genepharm (Shanghai, China). All siRNAs were subjected to BLAST search to ensure the absence of hits with $>17$ nucleotide matches found in the corresponding genomes. Transfection was carried out using 100 pmol of siRNA and Lipofectamine ${ }^{\circledR} 3000$ reagent (Invitrogen; Thermo Fisher Scientific, Inc.) according to the manufacturer's protocol. The medium was changed after $6 \mathrm{~h}$.

Flow cytometric analysis of apoptosis. Following treatment with DMSO or muscone for $24 \mathrm{~h}$, the apoptotic nuclear morphology of HepG2 cells was observed under a fluorescence microscope at an $\times 40$ magnification (Olympus IX71) with $2 \mu \mathrm{g} / \mathrm{ml}$ DAPI staining (Sigma-Aldrich; Merck KGaA) for $20 \mathrm{~min}$ at room temperature. Cells were subsequently double stained with an Annexin V-FITC/propidium iodide (PI) kit (Nanjing KeyGen Biotech Co., Ltd.), according to the manufacturer's protocol. Apoptotic cells were subsequently analyzed using a flow cytometer (BD Pharmingen; BD Biosciences). The data were analyzed using FlowJo software (version 7.6.1; Tree Star, Inc., Ashland, OR, USA).

Hoechst 33342 staining. Cells were plated into 6-well plates at a density of $1 \times 10^{5}$ cells per well and pretreated with $1 \mathrm{mM} 3-\mathrm{MA}$ (Selleck Chemicals) for $2 \mathrm{~h}$, prior to treatment with muscone. Cells were rinsed three times with PBS and then stained with $10 \mu \mathrm{g} / \mathrm{ml}$ Hoechst 33342 (Sigma-Aldrich; Merck KGaA) for $15 \mathrm{~min}$ at $37^{\circ} \mathrm{C}$ before being washed three times with PBS for a second time. Stained cells were observed under a fluorescence microscope at an x200 magnification (Olympus IX71). Apoptotic cells were identified by the fragmentation of nuclei 
and condensation of chromatin, and the apoptotic index was calculated using the following equation: Number of apoptotic cells/total cell count. Experiments were performed in triplicate.

Autophagy assay. Following incubation with DMSO or muscone at $37^{\circ} \mathrm{C}$ for $24 \mathrm{~h}, 3 \times 10^{4}$ cells/well were stained with monodansylcadaverine (MDC, $0.1 \mathrm{mmol} / \mathrm{l}$; Nanjing KeyGen Biotech Co., Ltd.) for $25 \mathrm{~min}$ at $37^{\circ} \mathrm{C}$ and observed using a fluorescence microscope (Olympus IX71) at an x100 magnification. The fluorescence intensity was analyzed using a Varioskan Flash fluorescence microplate reader (Thermo Fisher Scientific, Inc.).

To examine the formation of autophagosomes, a total of $3 \times 10^{4}$ cells/well were plated into 48 -well plates and $\sim 24 \mathrm{~h}$ later, the cells were rinsed three times PBS. Subsequently, cells were treated with $1 \mathrm{mg} / \mathrm{ml}$ acridine orange (AO; Nanjing KeyGen Biotech Co., Ltd.) for $30 \mathrm{~min}$ at $37^{\circ} \mathrm{C}$, and then rinsed again three times with PBS. Stained cells were visualized using a fluorescence microscope at an x100 magnification (Olympus IX71) and the percentage of acidic vesicular organelle (AVO)-positive cells with $\geq 10$ AVO aggregations was calculated and analyzed statistically ( $\geq 600$ cells were observed). Experiments were performed in triplicate.

Reverse transcription-quantitative PCR (RT-qPCR). Total RNA was extracted using TRIzol ${ }^{\circledR}$ reagent (Invitrogen; Thermo Fisher Scientific, Inc.) and subsequently treated with DNase I (Thermo Fisher Scientific, Inc.). Total RNA was reverse transcribed into cDNA using random hexamer primers and RevertAid Reverse Transcriptase (Thermo Fisher Scientific, Inc.). qPCR was subsequently performed using a SYBR ${ }^{\circledR}$ Premix Ex Taq II kit (Takara Biotechnology Co., Ltd.) and a StepOnePlus Real-time PCR System (Applied Biosystems; Thermo Fisher Scientific, Inc.). The following primer pairs were used for the qPCR: AFT4 forward, 5'-GTC AGTCCCTCCAACAACAGCAA-3' and reverse, 5'-GAA GGTCATCTGGCATGGTTTCC-3'; DDIT3 forward, 5'-TTG CCTTTCTCCTTCGGGACACT-3' and reverse, 5'-CTTGTG ACCTCTGCTGGTTCTGG; FGF21 forward, 5'-CTGGAG ATCAGGGAGGATGGGA-3' and reverse, 5'-FCGTGGGCT TCGGACTGGTAAA-3'; TRIB3 forward, 5'-AAGCGGTTG GAGTTGGATGAC-3' and reverse, 5'-CACGATCTGGAG CAGTAGGTG-3'; SESN2 forward, 5'-AAGGACTACCTG CGGTTCG-3' and reverse, 5'-CGCCCAGAGGACATCAGT G-3'; and GAPDH forward, 5'-CCATGTTCGTCATGGGTG TGAACCA-3' and reverse, 5'-GCCAGTAGAGGCAGGGAT GATGTTC-3'. Expression levels were quantified using the $2^{-\triangle \Delta \mathrm{Cq}}$ method (23) and GAPDH was used as the internal reference control. The thermocycling conditions were as follows: $95^{\circ} \mathrm{C}$ for $3 \mathrm{~min}$, followed by 40 cycles of $95^{\circ} \mathrm{C}$ for $15 \mathrm{sec}$, $60^{\circ} \mathrm{C}$ for $15 \mathrm{sec}, 72^{\circ} \mathrm{C}$ for $20 \mathrm{sec} ; 95^{\circ} \mathrm{C}, 15 \mathrm{sec} ; 60^{\circ} \mathrm{C}, 1 \mathrm{~min}$; $95^{\circ} \mathrm{C}, 15 \mathrm{sec} ; 60^{\circ} \mathrm{C}, 15 \mathrm{sec}$. Each sample was determined in duplicate. All PCR products were confirmed by $2.0 \%$ agarose gel electrophoresis.

Whole transcriptome library preparation and sequencing. Novogene Bioinformatics Technology Cooperation prepared the whole transcriptome libraries and performed deep sequencing. Following incubation with DMSO or muscone for $24 \mathrm{~h}$, total RNA from HepG2 cells was extracted. Total RNA was quantified using a K5500 micro-spectrophotometer (Drawell International Technology Co., Ltd.) and the quality was determined using an Agilent 2200 TapeStation system (Agilent Technologies, Inc.). Ribosomal RNA was removed following the generation of strand-specific sequencing libraries, according to the manufacturer's protocol (Novogene Co., Ltd.). RNA sequencing (RNA-Seq) was performed using an Illumina HiSeq 2000 platform and 100 bp paired-end reads were generated according to the manufacturer's protocol (Illumina, Inc.).

RNA-Seq data analysis. Raw image data obtained from high-throughput sequencing(IlluminaHiSeqTMPE125/PE150) were processed by CASAVA (version 1.8.2; Illumina, Inc.) for base calling and sequenced reads were obtained. Raw data were stored as FASTQ files, and raw reads with adapters and low-quality portions were filtered to obtain clean reads for subsequent analysis. TopHat2 (version 2.1.1) was used to map the reads to the reference genome. During RNA-Seq analysis, expression levels were determined by counting the reads that were mapped to genomic regions or exons. Subsequently, fragments/kilobases/million reads were used for differential expression analysis. Pathway enrichment associated with differentially expressed genes (DEGs) was performed using hypergeometric analysis of corresponding Kyoto Encyclopedia of Genes and Genomes (KEGG) pathways (http://www. genome.jp/kegg/ or http://www.kegg.jp/).

Western blotting. Cells were lysed using NP-40 lysis buffer (50 mM Tris-HCl, pH 7.4, $150 \mathrm{mM} \mathrm{NaCl,} \mathrm{1 \%} \mathrm{NP-40,}$ $0.5 \% \mathrm{NaDC}, 0.1 \% \mathrm{SDS}$ ) containing a protease inhibitor cocktail proteinase inhibitor cocktail solution (Roche, Basel, Switzerland). Total protein in cell lysates was quantified using a bicinchoninic acid protein assay kit (Thermo Fisher Scientific, Inc.). Equal amounts $(30 \mu \mathrm{g})$ of protein were separated by $10 \%$ SDS-PAGE. Separated proteins were subsequently transferred onto nitrocellulose membranes and blocked with PBS-0.2\% Tween-20 (PBST) containing 5\% skimmed milk powder (SMP) at room temperature for $1 \mathrm{~h}$. The membranes were incubated overnight at $4^{\circ} \mathrm{C}$ with primary antibodies in PBST containing 5\% SMP. The membranes were subsequently washed five times with PBST and incubated with secondary antibodies $(1: 10,000)$ in PBST containing 5\% SMP at room temperature for $1 \mathrm{~h}$. Membranes were washed five times with PBST and protein bands were visualized on X-ray film (Carestream Health, Inc.) using ECL chemiluminescence reagents (Thermo Fisher Scientific, Inc.), with $\beta$-actin as the loading control. Protein expression was quantified using Image J $1.51 \mathrm{k}$ software (National Institutes of Health).

Cell viability assay. Cells $\left(1 \times 10^{4}\right)$ were incubated with muscone (concentrations of $0.5,1,1.5,2$ and $2.5 \mu \mathrm{M}$ ) or a corresponding volume of DMSO for $24 \mathrm{~h}$, and cell viability was measured using a Cell Counting Kit-8 assay (CCK-8; Nanjing KeyGen Biotech Co., Ltd.), according to the manufacturer's protocol. Brielfly, $10 \mu \mathrm{l}$ of CCK-8 solution was added to each well followed by $1 \mathrm{~h}$ of incubation at $37^{\circ} \mathrm{C}$. Subsequently, the absorbance value (OD) of the cells at $450 \mathrm{~nm}$ was measured by using a universal microplate spectrophotometer (BioTek Instruments, Inc.). 
Animal studies. All animal studies were approved by the Committee on the Use of Live Animals in Teaching and Research of Sichuan University, and were conducted in accordance with approved guidelines. BALB/c nude mice (number, 20; age, 6 weeks; sex, male; weighing approximately 18-22 g) were obtained from Chengdu Dossy Biological Technology Company (http://www.cd-dossy.cn/intro/50.html) (Chengdu, China; certificate no: SCXK Sichuan 2015-030). All mice were maintained under special pathogen-free conditions, with temperature maintained at $23 \pm 2^{\circ} \mathrm{C}$, humidity of $60 \pm 10 \%, 12 \mathrm{~h}$ light-dark cycle with free access to standard rodent chow and water. A total of $3 \times 10^{6} \mathrm{HepG} 2$ cells were resuspended in $0.2 \mathrm{ml}$ serum-free DMEM with $50 \%$ Matrigel (Corning, Inc.) subcutaneously injected into the lateral flank of mice and 14 days later, mice with an average tumor diameter of $6 \mathrm{~mm}$ were selected for the intraperitoneal injection of $0.1 \mathrm{mmol} / \mathrm{kg}, 0.2 \mathrm{ml} / 20 \mathrm{~g}$ bw DMSO or muscone. Maximum tumor diameter exceeding $15 \mathrm{~mm}$ was deemed the humane endpoint of the study. The mice were sacrificed by $\mathrm{CO}_{2}$ exposure followed by cervical dislocation and efforts were made to minimize suffering. Then xenograft tumors were collected and measured.

Patient studies. The present study was approved by the Institutional Ethics Committee of the Changchun University of Traditional Chinese Medicine (approval no. CCZYFYCC2017-071) and adhered to the principles in the Declaration of Helsinki. Informed consent was obtained from each patient prior to tissue collection for experimentation. A total of 14 human HCC tissue samples were obtained from the Affiliated Hospital of Changchun University of Chinese Medicine (age range, 40-55 years; 10 males and 4 females; collected from March 2016 to March 2017). All tissues were collected from patients who underwent surgery at the hospital. The patients were diagnosed with HCC based on pathology and all patients had no history of anticancer therapy. All of the specimens were examined and evaluated by two independent pathologists. The tissues were snap-frozen and stored in liquid nitrogen immediately after dissection until required for further analysis using western blotting and RT-qPCR.

Statistical analysis. Statistical analysis was performed using GraphPad Prism version 6 software (GraphPad Software, Inc.) and based on three independent experiments; data are expressed as the mean $\pm \mathrm{SD}$. Student's t-tests was used to determine statistical differences between groups. Differences among three or more groups were compared using one-way ANOVA followed by a Tukey's test. $\mathrm{P}<0.05$ was considered to indicate a statistically significant difference.

\section{Results}

Muscone inhibits the growth of liver cancer cells. To investigate the effects of muscone on the cell viability of liver cancer cells, HepG2 and Hep3B cells were treated with muscone (0.5, $1,1.5,2$ and $2.5 \mu \mathrm{M}$ ) for $24 \mathrm{~h}$. Results from the CCK-8 assay demonstrated that the viability of cells treated with muscone was significantly decreased compared with cells treated with DMSO, with muscone exhibiting a dose-dependent effect on cell viability (Fig. 1A and C). HepG2 cells were observed to be more sensitive to muscone treatment (Fig. 1A and C), with a half maximal inhibitory concentration $\left(\mathrm{IC}_{50}\right)$ value of $0.663 \mu \mathrm{M}$, whereas the Hep3B $\mathrm{IC}_{50}$ value was $1.416 \mu \mathrm{M}$. Whilst the corresponding volume of DMSO had no effect on cell growth, $0.663 \mu \mathrm{M}$ muscone significantly inhibited cell growth following 24 and $48 \mathrm{~h}$ of treatment (Fig. 1B and D). Thus, $0.663 \mu \mathrm{M}$ muscone and the corresponding volume of DMSO were used in the following HepG2 cell experiments. To further identify whether muscone treatment affected other malignant tumors, $1 \mu \mathrm{M}$ muscone was used to treat malignant tumor cell lines A549 and HCT116, and was found to significantly inhibit the cell viability compared with the control group (Fig. 1E and F).

Muscone induces HepG2 cell apoptosis and autophagy. Next, it was investigated whether the effect of muscone treatment on the survival of HepG2 cells was associated with apoptosis. HepG2 cells treated with muscone and stained with DAPI demonstrated an apoptotic phenotype (Fig. 2A). Cells were subsequently subjected to double staining with Annexin V-FITC/PI and examined by flow cytometry. The apoptotic rate of HepG2 cells was significantly increased following treatment with muscone compared with the control (Fig. 2B). Apoptosis is induced following the cleavage and subsequent activation of pro-caspase-3 (24-26), as caspase-3 is an important regulator of apoptosis in the downstream caspase cascade reaction $(27,28)$. Bcl-2 and Bax proteins belonging to the $\mathrm{Bcl}-2$ family are also important regulators of apoptosis (29), thus the expression levels of Bax, $\mathrm{Bcl}-2$ and caspase-3 proteins were analyzed using western blotting (Fig. 2C). Following treatment of HepG2 cells with muscone, the expression levels of cleaved caspase- 3 and Bax proteins were markedly increased, whereas those of the $\mathrm{Bcl}-2$ protein were decreased compared with the control.

To investigate the effect of muscone on autophagy within HepG2 cells, AVOs were visualized using MDC staining and AO staining (Fig. 2D and E) (30). Muscone treatment significantly increased the percentage of AVO-positive HepG2 cells, which was demonstrated using fluorescence analysis (Fig. 2F) and cell counts (Fig. 2G). Moreover, western blotting was used to analyze the expression levels of microtubule-associated proteins 1A/1B light chain 3 (LC3) II protein, the lipidated form of LC3 associated with the autophagosome membrane (31), in the HepG2 cells and it was demonstrated that LC3 II expression levels were markedly increased following muscone treatment (Fig. 2H and I). These results suggest that muscone treatment may induce apoptosis and autophagy in HepG2 cells.

Muscone-induced HepG2 cell apoptosis is associated with endoplasmic reticulum (ER) stress through the PERK/ATF4/DDIT3 signaling pathway. To determine the molecular mechanism used by muscone to induce apoptosis, transcriptome sequencing analysis was performed in HepG2 cells treated with muscone. The differentially expressed genes (DEGs) [llog2 (fold-changel) $>1$ and q-value $<0.005]$ were screened according to the two threshold values: Fold-change and significance level. A total of 170 genes demonstrated differential expression following muscone treatment, of which 131 genes had increased expression levels and 39 genes were found to have reduced expression 
A

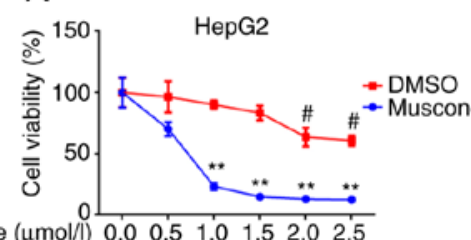



C

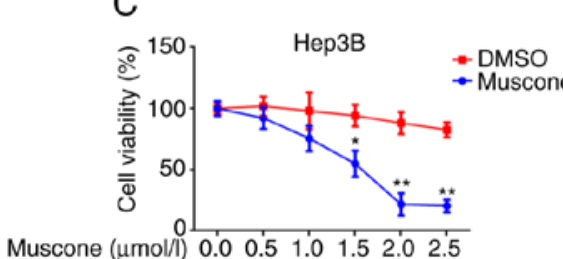

B

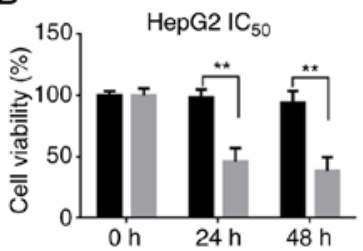

D

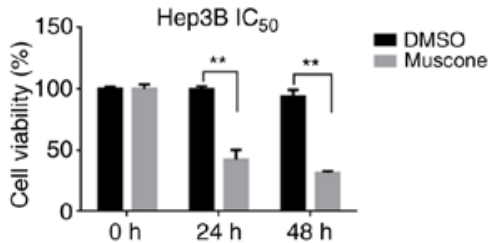

E
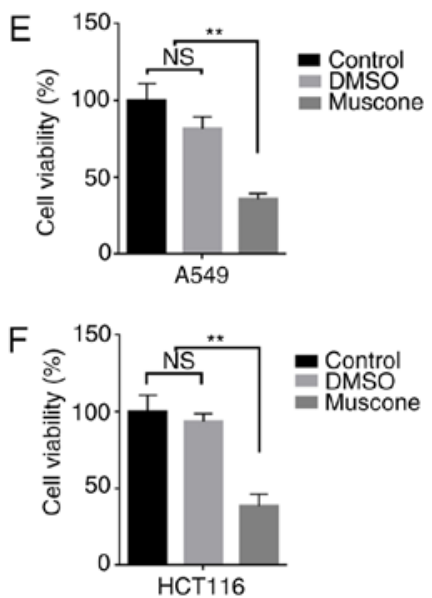

Figure 1. Muscone inhibits tumor cell viability. (A) Cell viability and $\mathrm{IC}_{50}$ of HepG2 cells treated with $0,0.5,1,1.5,2$ or $2.5 \mu \mathrm{Mol} / 1$ muscone or DMSO for $24 \mathrm{~h}$ were determined using CCK-8 assays. (B) Cell viability of HepG 2 cells was determined using CCK-8 assays following treatment with $0.663 \mu$ M muscone or the corresponding volume of DMSO for 24 or $48 \mathrm{~h}$. (C) Cell viability and $\mathrm{IC}_{50}$ of Hep3B cells treated with $0,0.5,1,1.5,2$ or $2.5 \mu \mathrm{Mol} / 1 \mathrm{muscone}$ or DMSO for $24 \mathrm{~h}$ was determined using CCK-8 assays. (D) Cell viability of Hep3B cells was determined using CCK-8 assays following treatment with $0.663 \mu \mathrm{M}$ muscone or the corresponding volume of DMSO for 24 or 48 h. (E and F) Cell viability of (E) A549 and (F) HCT116 cells treated with $1 \mu$ M muscone or DMSO for $24 \mathrm{~h}$ was assessed using a CCK-8 assay. Control represents cells that did not receive treatment. ${ }^{*} \mathrm{P}<0.05$, ${ }^{* *} \mathrm{P}<0.01$ vs. Control group; ${ }^{\sharp} \mathrm{P}<0.05$ vs. muscone group; $\mathrm{n}=3$; NS, not significant; $\mathrm{IC}_{50}$, half maximal inhibitory concentration; CCK-8, Cell Counting Kit-8.

A

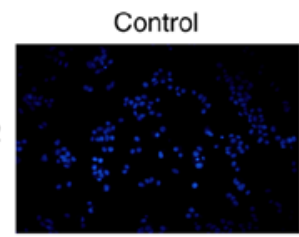

B

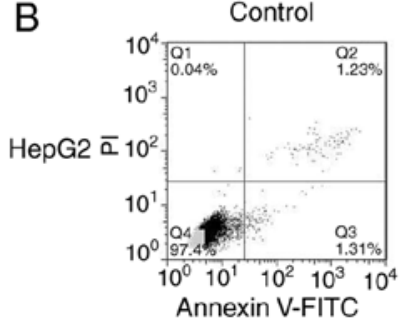

D

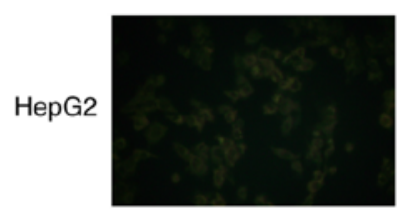

$E$

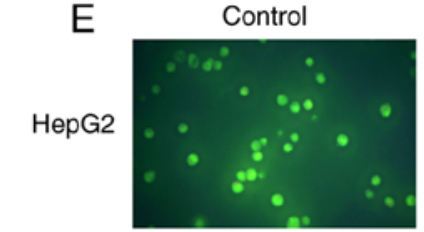

DMSO
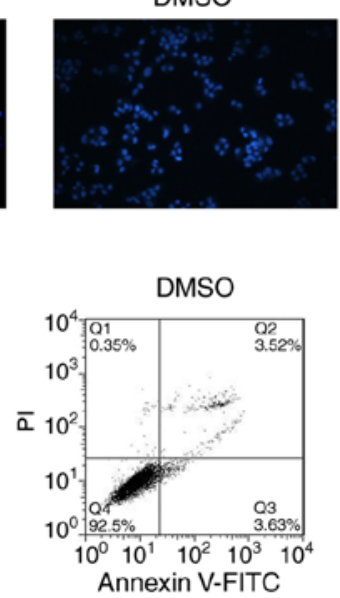

DMSO

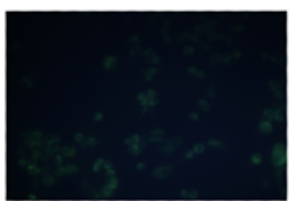

DMSO

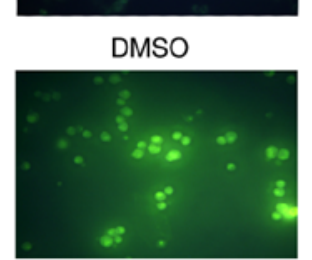

Muscone

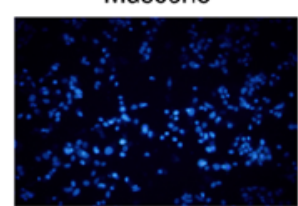

C

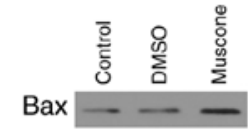

$\mathrm{Bcl}-2$

Pro caspase-3 $-\infty$

Cleaved

caspase-3

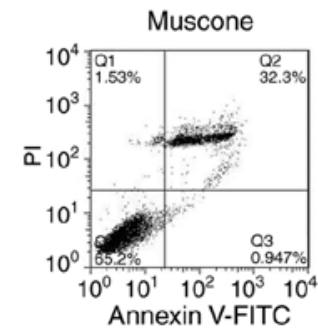

Actin

$--$
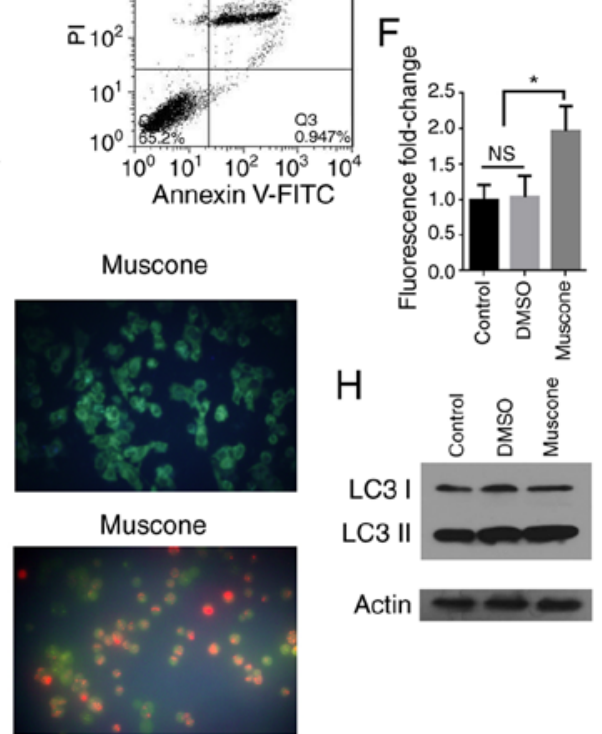

G
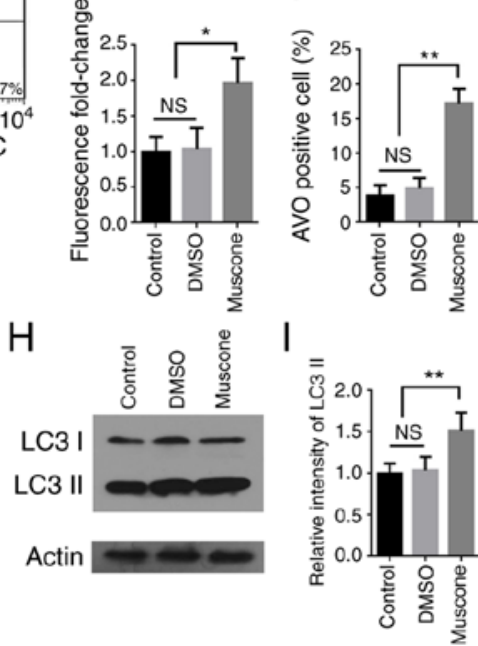

Figure 2. Muscone induces apoptosis and autophagy in HepG2 cells. (A) HepG2 cells were treated with DMSO or muscone for $24 \mathrm{~h}$, and then stained with DAPI and examined by fluorescence microscopy at an x40 magnification (Olympus IX71). Blue staining represents the cell nucleus and the control represents cells that did not receive treatment. (B) HepG2 cells were treated with DMSO or muscone for $24 \mathrm{~h}$ and subsequently double stained with Annexin V-FITC/PI. Apoptosis was analyzed using flow cytometry. (C) HepG2 cells were treated with DMSO or muscone for $24 \mathrm{~h}$ and the protein expression levels of Bax, Bcl-2, pro-caspase-3 and cleaved caspase-3 were analyzed using western blotting. (D and E) Representative micrographs (x100 magnification, Olympus IX71) of (D) MDC and (E) AO staining following treatment of HepG2 cells with DMSO or muscone for $24 \mathrm{~h}$. (F) MDC fluorescence intensity fold-change was semi-quantified using a fluorescence microplate reader. (G) Positive AO staining and cell counting. (H) HepG2 cells were treated with DMSO or muscone for $24 \mathrm{~h}$ and LC3 I and LC3 II expression levels were analyzed using western blotting. (I) LC3 II levels were quantified by densitometric analysis relative to LC3 I. Error bars represent the standard deviations for $\mathrm{n}=3 .{ }^{*} \mathrm{P}<0.05,{ }^{* *} \mathrm{P}<0.01 ; \mathrm{n}=3$; NS, not significant; PI, propidium iodide; MDC, monodansylcadaverine; AO, acridine orange; LC3, light chain 3 . 




$\mathrm{H}$


B
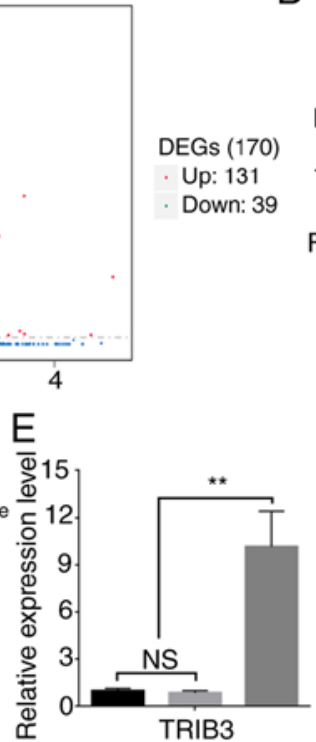

TRIB3
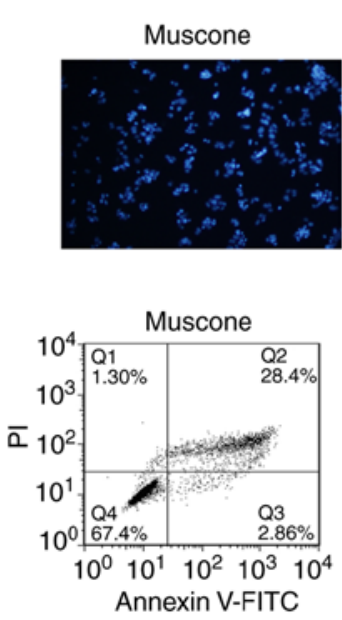

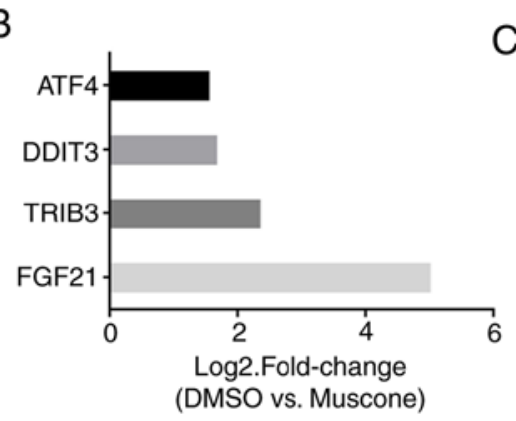

$\mathrm{F}$
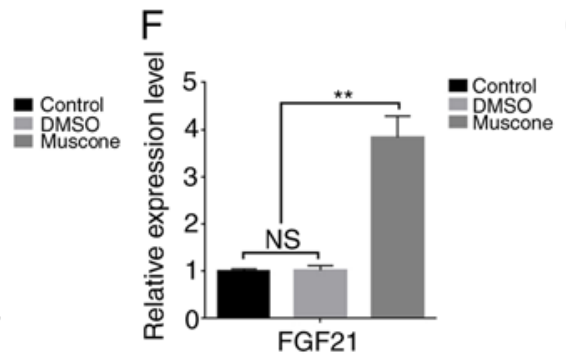

G

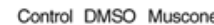

p-elF2 $\alpha$
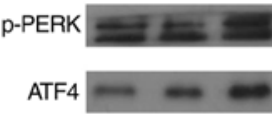

DDIT3

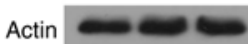

J Control Muscone Muscone +4. PBA

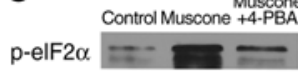

p-PERK



DDIT3 -


Figure 3. Transcriptome sequencing and gene expression analysis of HepG2 cells revealed that muscone influences the expression levels of genes associated with ER stress. (A) Volcano plot demonstrating the DEGs identified in HepG2 cells following muscone treatment. Overall, 131 upregulated genes and 39 downregulated genes were identified in the muscone group compared with the DMSO group. DEGs were screened according to fold-change and significance level [llog2 (Fold Change) I >1 and q-value <0.005]. Red, upregulated; green, downregulated; blue, no change. (B) Fold-change of genes associated with ER stress (ATF4, DDIT3, TRIB3 and FGF21) in HepG2 cells (DMSO vs. muscone) following transcriptome sequencing and gene expression analysis. (C-F) Reverse transcription-quantitative PCR analysis of (C) ATF4, (D) DDIT3, (E) TRIB3 and (F) FGF21 expression levels in HepG2 cells treated with DMSO or muscone for $24 \mathrm{~h}$. Expression levels were normalized to the control group (no treatment). (G) Expression levels of proteins involved in the PERK/ATF4/DDIT3 signaling pathway in HepG2 cells treated with DMSO or muscone for $24 \mathrm{~h}$ were detected using western blotting. (H) Effects of 4-PBA treatment on muscone-induced apoptosis. Apoptotic cells were stained with DAPI and visualized using a microscope at an x40 magnification (Olympus IX71). (I) Apoptotic rate was determined in muscone and muscone + 4-PBA treated cells using flow cytometry based on the percentage of Annexin V/FITC-positive cells. (J) Expression levels of PERK/ATF4/DDIT3 signaling pathway-related proteins were detected using western blotting. (K) Effects of 4-PBA inhibition on muscone cell viability in HepG 2 cells. ${ }^{* *} \mathrm{P}<0.01$ vs. control group; ${ }^{*} \mathrm{P}<0.05$ vs. muscone group; $\mathrm{n}=3$; NS, not significant. PI, propidium iodide; DEGs, differentially expressed genes; ER, endoplasmic reticulum; ATF4, anti-activating transcription factor 4; DDIT3, anti-DNA damage inducible transcript 3; TRIB3, Tribbles pseudokinase 3; FGF21, fibroblast growth dactor 21; 4-PBA, 4-phenyl butyric acid.

levels (Fig. 3A). Statistical analysis of these data indicated that genes associated with ER stress, such as ATF4, DDIT3, TIRB3 and FGF21 (32-35), had markedly increased expression levels (Fig. 3B). These results were further confirmed by RT-qPCR analysis (Fig. 3C-F). This indicated that muscone treatment may induce HepG2 cell apoptosis through ER stress. The DDIT3 transcription factor is an important pro-apoptotic factor in ER stress that is highly expressed under such conditions (36). It is activated by three transmembrane signaling proteins on the ER membrane, including PERK (37), and during periods of excessive or long-lived ER stress, activated
PERK forms a complex with eIF2 $\alpha$ and ATF4 to induce DDIT3 expression $(38,39)$. DDIT3 subsequently accumulates in the nucleus, promoting apoptosis and inhibiting the expression of the anti-apoptotic protein, Bcl-2 (40). Since ATF4 and DDIT3 expression levels were significantly increased following muscone treatment compared with the control (Fig. 3C and D), it was hypothesized that muscone may induce HepG2 cell apoptosis through the PERK/ATF4/DDIT3 signaling pathway. To verify this, the changes in the expression levels of relevant proteins in this pathway were investigated. Muscone treatment markedly increased the phosphorylation levels of PERK and 
eIF $2 \alpha$ proteins, and the expression levels of ATF4 and DDIT3 in the downstream signaling pathway (Fig. 3G). To confirm the effects of ER stress on muscone-induced growth inhibition, ER stress was blocked by treatment with $3 \mathrm{mM} 4$-PBA for $1 \mathrm{~h}$, followed by treatment with muscone for $24 \mathrm{~h}$. DAPI staining and flow cytometric analysis revealed that 4-PBA treatment inhibited muscone-induced apoptosis (Fig. 3H and I). Compared with the muscone treatment group, 4-PBA treatment markedly decreased the phosphorylation of PERK and eIF2 $\alpha$ proteins, as well as the protein expression levels of ATF4 and DDIT3 (Fig. 3J), 4-PBA treatment also partially reversed muscone-induced cell viability inhibition (Fig. 3K). These results further confirmed that muscone may induce HepG2 cell apoptosis through the PERK/ATF4/DDIT3 signaling pathway.

Muscone induces HepG2 cell autophagy through the SESN2/AMPK/mTOR1 signaling pathway. To further investigate which autophagy-related signaling pathways are regulated by muscone, transcriptome sequence analysis of HepG2 cells treated with DMSO or muscone was performed. GO analysis demonstrated that the function of DEGs was associated with 'aminoacyl tRNA ligase activity', 'synthesis pathways' and 'organic nitrogen complex metabolic pathways' (data not shown). KEGG pathway analysis reported that the DEGs were mainly enriched in the following pathways: 'One-carbon pool by folate', 'peroxisome', 'fatty acid metabolism (degradation, synthesis and metabolism)', 'pyruvate metabolism', 'p53 signaling', 'HIF-1 signaling', 'organic selenium compound metabolism', 'AMPK signaling' and 'PPAR signaling' (Fig. 4A). Western blotting further revealed that muscone increased AMPK expression levels and suppressed the mTOR pathway (Fig. 4B). Among the DEGs, the autophagy-related gene SESN2 (41) was reported to be highly activated by muscone treatment (Fig. 4C and D).

The involvement of SESN2 in muscone-associated autophagy was investigated further, and it was observed that the expression levels of SESN2 were significantly increased at both the mRNA and protein level by muscone treatment (Fig. 4E and F). Using siRNA targeting human SESN2 to knock down its endogenous expression in HepG2 cells, it was demonstrated that LC3 II expression levels were decreased in SESN2-knockdown cells treated with muscone compared with the control (Fig. 4G). In addition, SESN2 depletion significantly attenuated the muscone-mediated induction of AMPK and mTOR phosphorylation (Fig. 4H). AVOs were visualized using MDC staining and AO staining (Fig. 4I and J). Results showed a significantly reduced percentage of AVO-positive cells which was demonstrated using fluorescence analysis (Fig. 4K) and cell counts (Fig. 4L). These findings suggested that muscone may induce autophagy through the SESN2-mediated activation of the AMPK pathway.

Muscone induces autophagy-dependent apoptosis in HepG2 cells. Taken together, the results of the present study demonstrated that muscone triggered apoptotic cell death and simultaneously activated autophagy in liver cancer cells. To investigate whether autophagy affected muscone-induced apoptotic cell death, the autophagy inhibitor, 3-MA was used. Compared with the muscone group, the pretreatment of cells with 3-MA reduced muscone-induced autophagy, which was demonstrated through decreased expression levels of LC3 II (Fig. 5A and B). The 3-MA inhibitor relieved the muscone-induced chromatin condensation in HepG2 cells and attenuated the muscone-induced increased expression levels of caspase-3 in HepG2 cells (Fig. 5C-E). Additionally, the pretreatment of cells with 3-MA relieved the significantly decreased levels of cell viability induced by muscone (Fig. 5F). These data demonstrated that the inhibition of autophagosome formation by 3-MA attenuated muscone-induced apoptosis, suggesting that muscone-induced apoptosis may be partially autophagy-dependent.

Muscone suppresses subcutaneous tumor growth in mice. The effects of muscone on tumor growth in vivo were subsequently investigated. HepG2 cells were injected subcutaneously into athymic nude mice as previously described (42). The transplantation of HepG2 cells into nude mice successfully induced the in-situ formation of liver cancer (Fig. 6A). Treatment with muscone for 1 week significantly reduced the tumor volume and weight compared with DMSO treatment (Fig. 6B-D). The role of apoptosis in muscone-inhibited subcutaneous tumor growth was analyzed. The apoptosis-related proteins, including Bax, Bcl-2 and caspase- 3 were assayed using western blotting of two different groups (group 1: No. 1 and No. 5 subcutaneous tumor in Fig. 6B; group 2: No. 2 and No. 6 subcutaneous tumor in Fig. 6B). The protein expression levels of cleaved caspase- 3 and Bax were markedly increased, whereas Bcl-2 expression levels were decreased in the muscone-treated group compared with the control (Fig. 6E). To further confirm that muscone induced subcutaneous tumor apoptosis via the PERK/ATF4/DDIT3 signaling pathway, the phosphorylation levels of eIF2 $\alpha$ and PERK, as well as the protein expression levels of ATF4 and DDIT3 were examined. Muscone treatment increased the expression levels of the PERK/ATF4/DDIT3 signaling pathway-related proteins compared with the DMSO group (Fig. 6E). Thus, the role of autophagy in muscone-induced inhibition of tumor growth was further investigated by analyzing the protein expression levels of p-AMPK, p-mTOR, SESN2 and LC3-II. Muscone treatment markedly increased the expression levels of p-AMPK, LC3-II and SENS2, and reduced the expression levels of $\mathrm{p}$-mTOR compared with the DMSO group (Fig. 6F). These results suggest that muscone may inhibit HCC-transplanted subcutaneous tumor growth in vivo by inducing apoptosis and autophagy.

Finally, the prognostic role of SESN2 expression levels in HCC was investigated. RT-qPCR and western blotting demonstrated that both SESN2 mRNA and protein expression levels were significantly decreased in the 14 human HCC tissues compared with the non-cancerous tissue samples (Fig. 6G and H). Thus, these findings indicated that SESN2 may be a potential candidate for understanding the molecular mechanisms of hepatocarcinogenesis, and especially for HCC diagnosis and therapy.

\section{Discussion}

In the present study, the effects of muscone on the induction of liver cancer cell apoptosis and autophagy were investigated. 
A

A One carbon pool by folate Fatty acid degradation Pyruvate metabolism Fatty acid metabolism Glycine, serine and threonine metabolism
Biosynthesis of amino acids
Ribosome Fatty acid degradome P53 signaling pathway
HIF-1 signaling pathway HIF-1 signaling pathway
elenocompound metabolism AMPK signaling pathway
AMocompond metablism AMPK signaling pathway
Fatty acid biosynthesis Fatty acid biosynthesis
Carbon metabolism PPAR signaling pathway Terpenoid backbone biosynthesis
Aminoacyl-tRNA biosynthesis Metabolic pathways Steroid biosynthesis

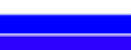

$+2$

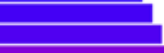

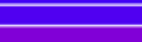
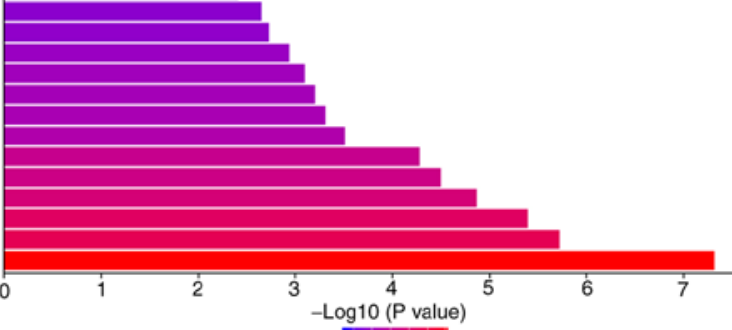

234567

C

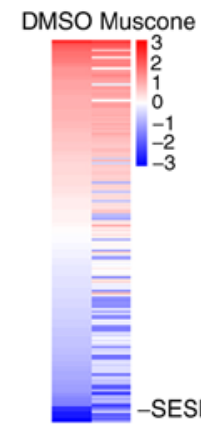

D

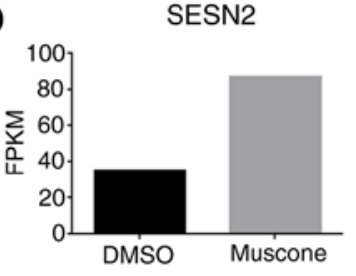

G


SESN2

Actin


$J$
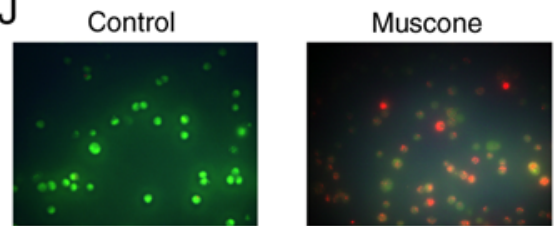

$\mathrm{K}$

HepG2
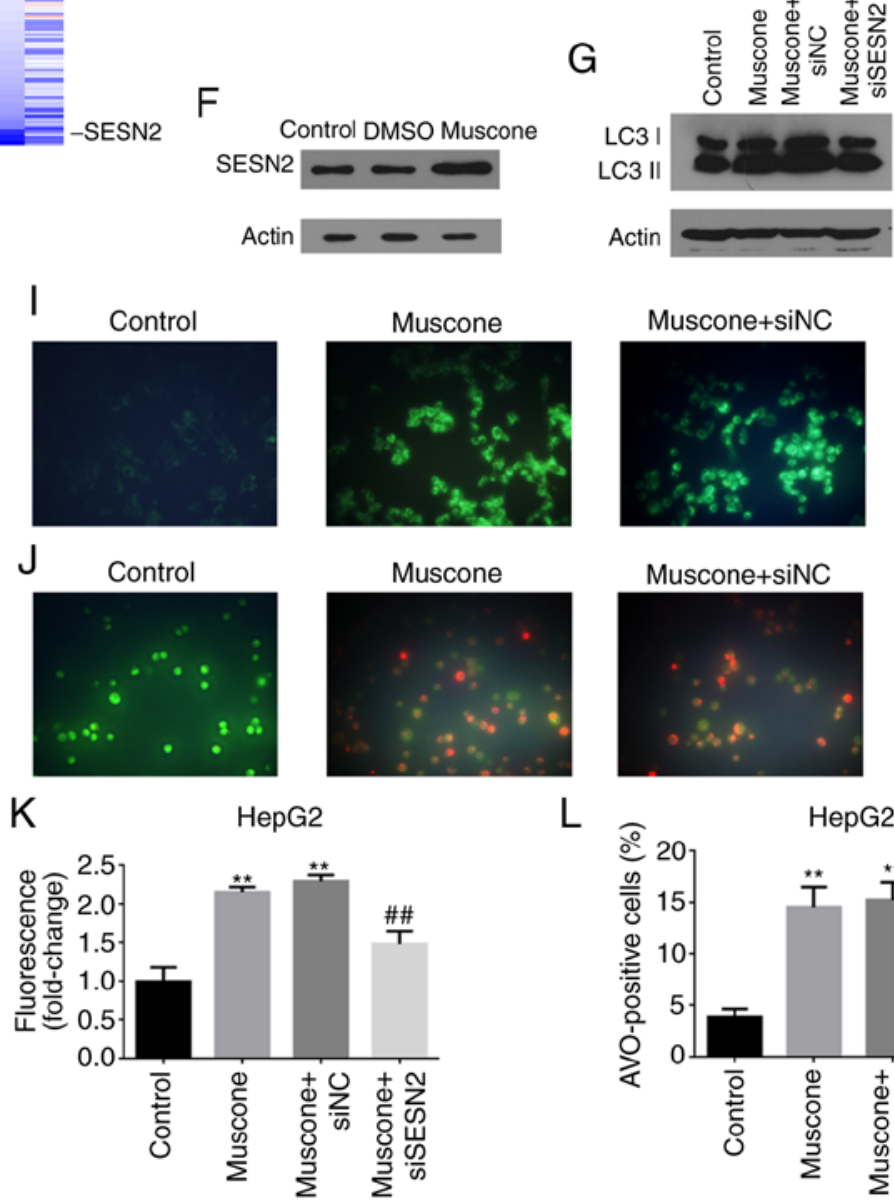

\section{L}

E

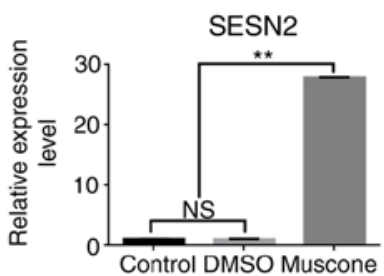

$\mathrm{B}$

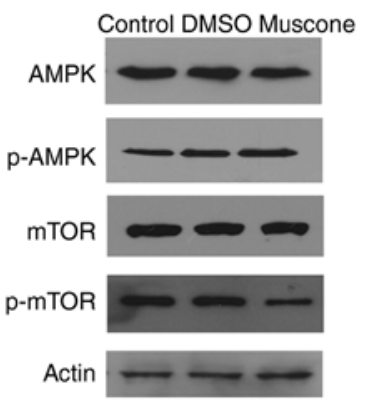

\section{$\mathrm{H}$}

AMPK

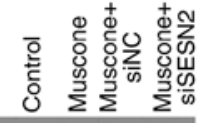

p-AMPK

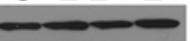

mTOR

p-mTOR

Actin
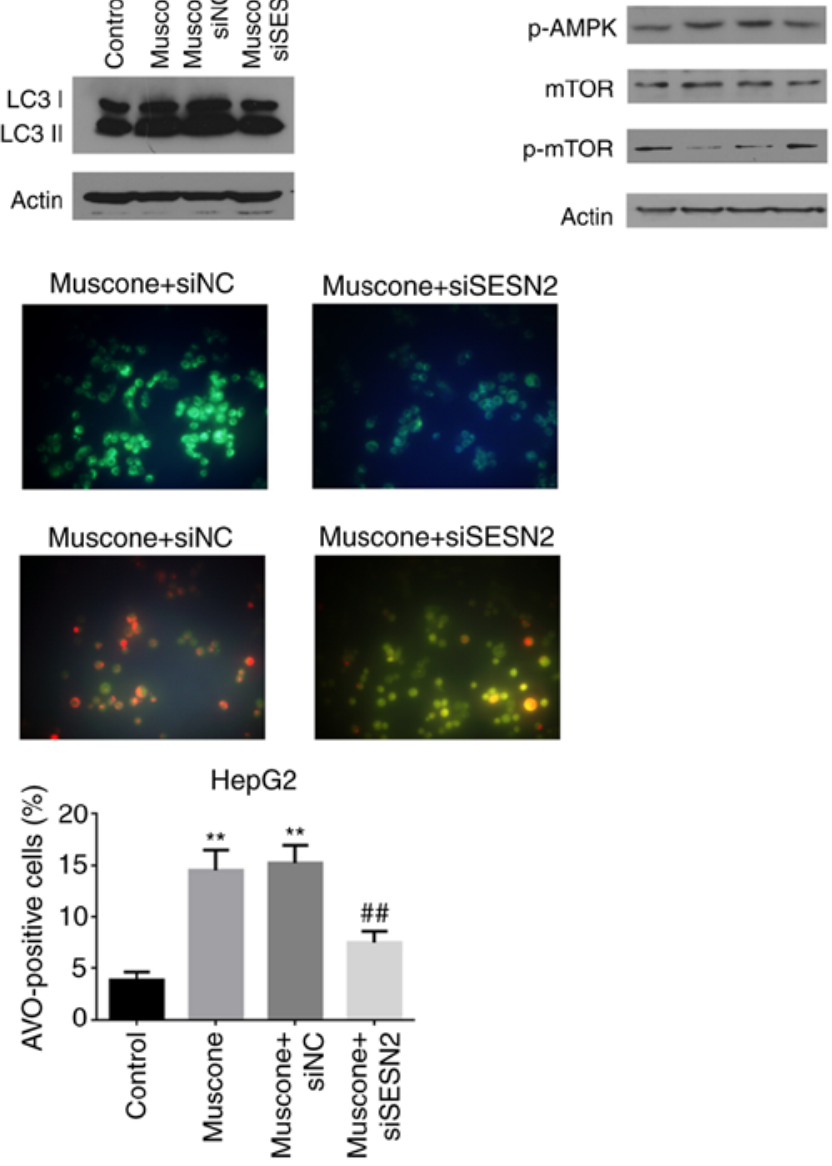

Figure 4. Muscone induces HepG2 cell autophagy through the SESN2/AMPK/mTOR1 signaling pathway. (A) Top Kyoto Encyclopedia of Genes and Genomes (KEGG) pathways enriched in HepG2 cells following treatment with DMSO vs. muscone. (B) Expression levels of AMPK/mTOR signaling pathway proteins in HepG2 cells treated with DMSO or muscone for $24 \mathrm{~h}$ were assessed using western blotting. (C) SESN2 gene expression is increased by muscone treatment. (D) FPKM of SESN2 expression identified by RNA-Seq. (E) Relative expression levels of SESN2 in HepG2 cells was assessed using reverse transcription-quantitative PCR following treatment with DMSO or muscone. (F) Expression levels of SESN2 in HepG2 cells treated with DMSO or muscone were assessed using western blotting. (G) LC3 protein expression levels in siSESN2-transfected HepG2 cells treated with muscone for $24 \mathrm{~h}$ were assessed using western blotting. (H) Phosphorylation of mTOR and AMPK in HepG2 cells was detected using western blotting in siSESN2-transfected HepG2 cells treated with muscone for $24 \mathrm{~h}$. (I and J) Representative micrographs of (I) MDC staining and (J) AO staining of HepG2 cells at an x100 magnification. (K) MDC fluorescence intensity fold-change was measured using a fluorescence microplate reader. (L) Positive AO staining cell counting. Densitometric analysis was performed using ImageJ software. ${ }^{* *} \mathrm{P}<0.01$ vs. control group; ${ }^{\# \#} \mathrm{P}<0.01$ vs. muscone group; $\mathrm{n}=3$; NS, not significant; MDC, monodansylcadaverine; AO, acridine orange; LC3, light chain 3; SESN2, anti-sestrin 2; AMPK, AMP-activated protein kinase; mTOR1, mechanistic target of rapamycin kinase 1. 
A
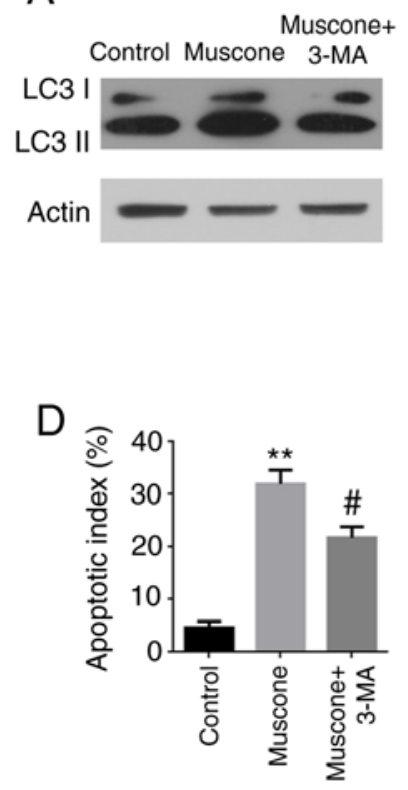

$\mathrm{B}$

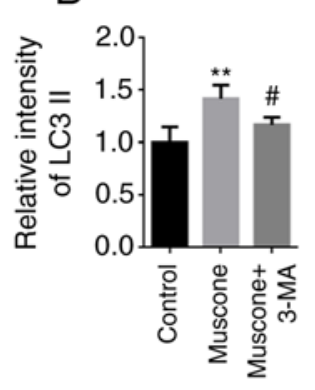

C
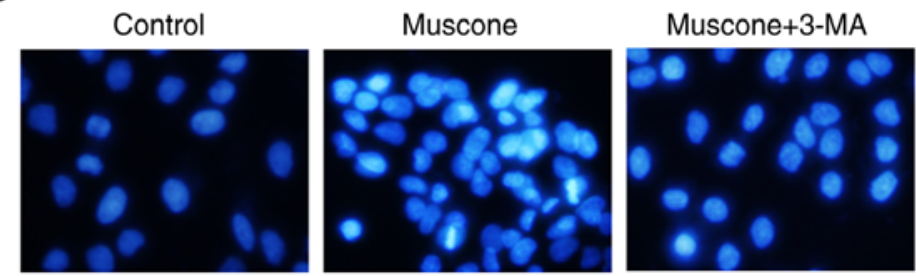

$E$

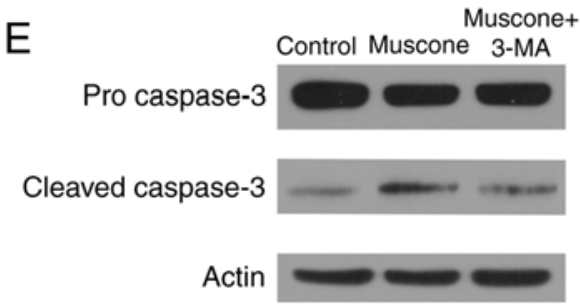

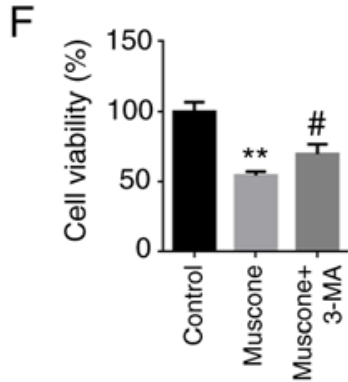

Figure 5. Effect of autophagy on muscone-induced apoptosis in HepG2 cells. HepG2 cells were pretreated with or without 1 mM 3-MA for 2 h, and then treated with muscone for $24 \mathrm{~h}$. (A) LC3 I and LC3 II expression levels were measured using western blotting. (B) LC3 II levels were quantified by densitometric analysis relative to LC3 I. Error bars represent the standard deviations for $n=3$. (C) Apoptotic nuclear changes were assessed using Hoechst staining at an x200 magnification (Olympus IX71). (D) Apoptotic index was determined using the micrographs obtained in part B. (E) Protein expression levels of pro-caspase-3 and cleaved caspase-3 in HepG2 cells were analyzed using western blotting. (F) Cell viability of HepG2 cells was measured using a Cell Counting Kit- 8 assay. ${ }^{* *} \mathrm{P}<0.01$ vs. control group; ${ }^{\#} \mathrm{P}<0.05$ vs. muscone group; $\mathrm{n}=3$. LC3, light chain 3; 3-MA, 3-methyladenine.

Muscone exhibited a broad range of antitumor activities that were mediated by apoptotic and autophagic pathways, which is consistent with that observed in previous clinical studies. Using RNA-Seq to detect differentially expressed genes (DEGs) and signaling pathways in HepG2 cells treated with muscone, it was demonstrated that ER stress was mediated by the muscone-induced PERK/ATF4/DDIT3 apoptotic pathway and the SENS2/AMPK autophagy signaling pathway. In vivo experiments also confirmed that the intraperitoneal injection of muscone inhibited the proliferation of transplanted tumors in nude mice; this inhibition was related to the PERK/ATF4/DDIT3 apoptotic signaling pathway and the SESN2/AMPK/mTOR autophagy signaling pathway.

In previous studies, both autophagy and apoptosis have been reported to occur in the same cells (43-46), and are suggested to intersect with each other through the mTOR and AMPK signaling pathways $(47,48)$. Several coinciding apoptotic signals, such as the AMPK signaling pathway and Bax have also been demonstrated to activate autophagy (49). In fact, autophagy-induced apoptosis has been reported by numerous studies $(50,51)$ and it is currently hypothesized that these processes most commonly occur in sequence, with autophagy preceding apoptosis (52). The results of the present study revealed that the inhibition of autophagosome formation attenuated muscone-induced apoptosis, suggesting that muscone-induced apoptosis may be partially autophagy-dependent. In support of autophagy-dependent apoptosis, it has been suggested that autophagy may function upstream of apoptosis and participate in the process of membrane blebbing by maintaining cellular ATP levels $(53,54)$; however, this possibility remains to be elucidated in future studies.
The present study indicated that the SESN2/AMPK/ mTOR pathway may be an important pathway for mediating muscone-induced autophagy in liver cancer cells. The SESN family of proteins consists of a highly conserved group of stress-inducible proteins with molecular weights ranging between 54-57 kDa. They are activated by different environmental stresses, such as DNA damage, oxidative stress and hypoxia, and following activation, they promote the recycling of peroxiredoxin through their sulfonic reductase activity to reduce the levels of reactive oxygen species (55). SESNs have also been reported to regulate the AMPK/mTOR complex 1 signaling pathway, which is involved in cellular autophagy $(56,57)$. Our study detected decreased expression levels of SESN2 in liver cancer tissues compared with paracancerous tissues (58), which provided clinical evidence that muscone may inhibit tumor development.

In conclusion, to the best of our knowledge, the findings from the present study were among the first to suggest that in addition to its analgesic effects, muscone may also induce liver cancer cell autophagy and apoptosis. Autophagy and apoptosis prevent necrosis-induced inflammatory responses in tumor tissues and ameliorate tissue pain caused by the compression induced by tumor growth. Another advantage of muscone is that its low toxicity prevents toxic inflammatory responses from occurring in healthy liver cells, which is of great importance for clinical practice. Thus, these findings revealed that muscone demonstrated potential for its use clinically as an anticancer drug, which may provide the basis for the development of more effective anticancer drugs derived from natural substances. Future studies are required to develop highly efficient anticancer drugs that target tumor cells. 
A

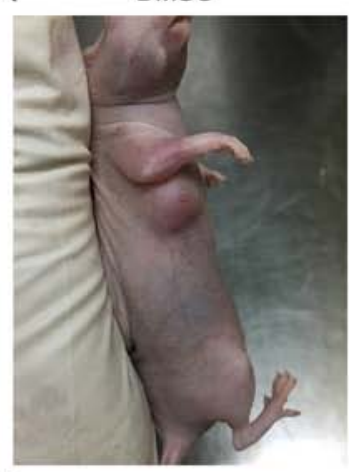

B



$\mathrm{E}$

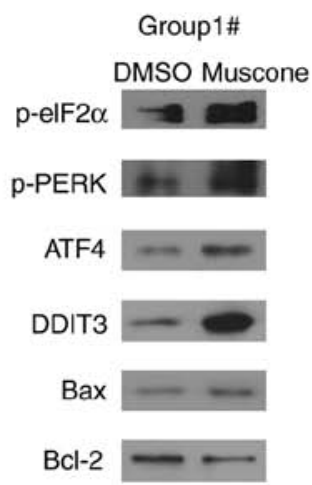

Pro caspase-3

Cleaved caspase-3

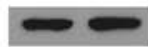

Actin


DMSO Muscone
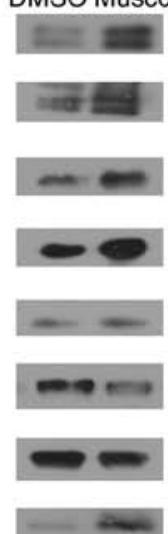

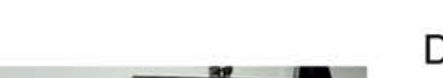

D

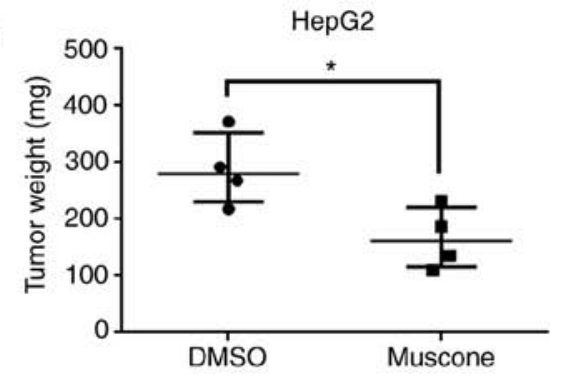

F
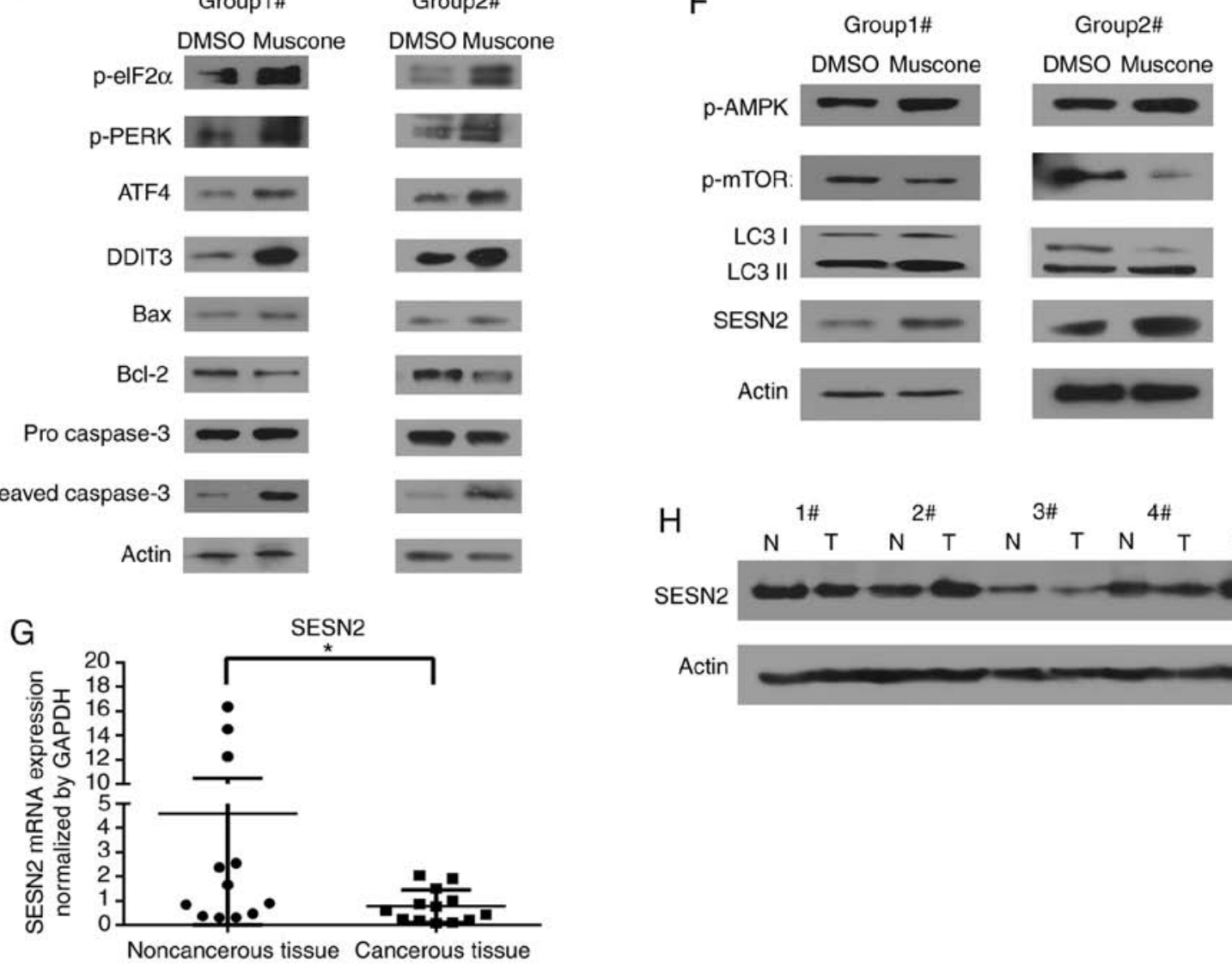

Actin
C

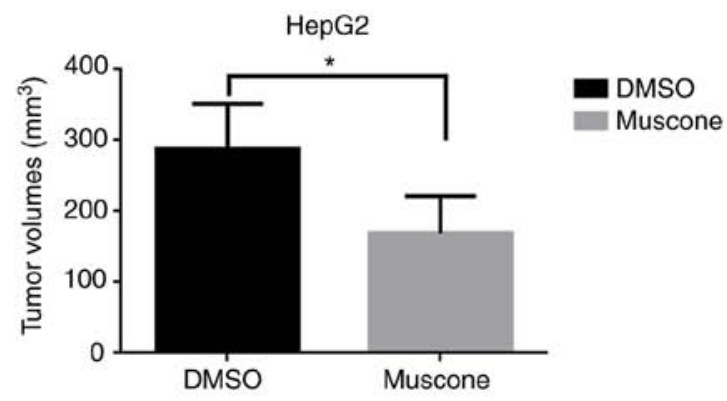

- DMSO

- Muscone
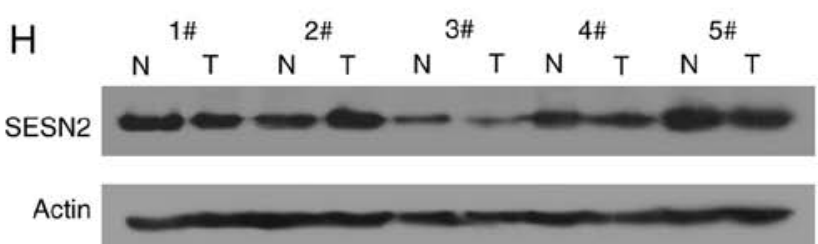

Figure 6. Effects of muscone on subcutaneous tumor growth in HepG2 cells. (A and B) Morphology of HepG2 cell subcutaneous tumors in BALB/c nude mice injected with HepG2 cells and treated with muscone (no. 5-8) or DMSO (no. 1-4). (C) Tumor volumes of BALB/c nude mice injected with HepG2 cells and treated with DMSO or muscone. (D) Tumor weight (in $\mathrm{mg}$ ) of subcutaneous tumors in BALB/c nude mice injected with HepG2 cells and treated with muscone or DMSO. (E) Expression levels of PERK/ATF4/DDIT3 signaling pathway-related proteins (p-eIF2 $\alpha$, p-PERK, ATF4 and DDIT3) and apoptosis-related markers (Bax, Bcl-2 and caspase-3) were detected by western blotting from two different groups of tumor tissues (group 1: no. 1 and no. 5 subcutaneous tumors; group 2: no. 2 and no. 6 subcutaneous tumors). (F) Western blotting was used to analyze the expression levels of autophagy-related markers in two different groups of tumor tissues (group 1: no. 1 and no. 5; group 2: no. 2 and no. 6). Actin was used as a loading control. (G) Reverse transcription-quantitative PCR analysis was used to analyze SESN2 expression levels in HCC tissues (T) compared with corresponding non-cancerous tissues (N). "P<0.05. (H) Western blotting was used to investigate SESN2 expression levels in 5 samples randomly selected from HCC tumor samples compared with corresponding non-cancerous tissue samples. p-eiF2 $\alpha$, phosphorylated eukaryotic initiation factor $2 \alpha$; p-PERK, phosphorylated protein kinase R-like endoplasmic reticulum kinase; ATF4, anti-activating transcription factor 4; DDIT3, anti-DNA damage inducible transcript 3; p-AMPK, phosphorylated AMP-activated protein kinase; p-mTOR1, phosphorylated mechanistic target of rapamycin kinase 1; SESN2, anti-sestrin 2. 


\section{Acknowledgements}

Not applicable.

\section{Funding}

The present study was supported by a grant from the National Natural Science Foundation of China (grant no. 31300674).

\section{Availability of data and materials}

The datasets used and/or analyzed during the current study are available from the corresponding author on reasonable request.

\section{Authors' contributions}

SX and LX designed the study; WQ, ZL, CY, JD, QZ, DW and CW performed the experiments and analyzed the data; SX and WQ wrote the manuscript; and LX and ZL revised the manuscript. All authors read and approved the final manuscript and agreed to be accountable for all aspects of the research in ensuring that the accuracy or integrity of any part of the work are appropriately investigated and resolved.

\section{Ethics approval and consent to participate}

This study was approved by the Institutional Ethics Committee of the Changchun University of Traditional Chinese Medicine (approval no. CCZYFYCC2017-071) and adhered to the principles in the Declaration of Helsinki. Informed consent was obtained from each patient before tissue collection for experimentation. All animal studies were approved by the Committee on the Use of Live Animals in Teaching and Research of Sichuan University, and were conducted in accordance with approved guidelines.

\section{Patient consent for publication}

Not applicable.

\section{Competing interests}

The authors declare that they have no competing interests.

\section{References}

1. World Health Statistics 2017: Monitoring health for the SDGs (https://www.who.int/gho/publications/world_health_statistics/2017/en/). WHO, May 17, 2017.

2. Schwarz RE and Smith DD: Trends in local therapy for hepatocellular carcinoma and survival outcomes in the US population. Am J Surg 195: 829-836, 2008.

3. Llovet JM, Di Bisceglie AM, Bruix J, Kramer BS, Lencioni R, Zhu AX, Sherman M, Schwartz M, Lotze M, Talwalkar J, et al: Panel of experts in HCC-design clinical trials in hepatocellular carcinoma. J Natl Cancer Inst 100: 698-711, 2008.

4. Yan L and Cheng P: Advances in treatment of advanced hepatocellular cancer. J Clin Hepatol 10: 47-60, 2014.

5. Moriguchi M, Umemura A and Itoh Y: Current status and future prospects of chemotherapy for advanced hepatocellular carcinoma. Clin J Gastroenterol 9: 184-190, 2016.

6. Llovet JM, Ricci S, Mazzaferro V, Hilgard P, Gane E, Blanc JF, de Oliveira AC, Santoro A, Raoul JL, Forner A, et al: Sorafenib in advanced hepatocellular carcinoma. N Engl J Med 359: 378-390, 2008.
7. Cheng AL, Kang YK, Chen Z, Tsao CJ, Qin S, Kim JS, Luo R, Feng J, Ye S, Yang TS, et al: Efficacy and safety of sorafenib in patients in the Asia-Pacific region with advanced hepatocellular carcinoma: A phase III randomised, double-blind, placebo-controlled trial. Lancet Oncol 10: 25-34, 2009.

8. Luo X: Clinical observation of compound musk injection for treating primary liver cancer pain. Guid J Tradit Chin Med Pharm 12: 41-43, 2014.

9. Lewandowski RJ, Kulik LM, Riaz A, Senthilnathan S, Mulcahy MF, Ryu RK, Ibrahim SM, Sato KT, Baker T, Miller FH, et al: A comparative analysis of transarterial downstaging for hepatocellular carcinoma: Chemoembolization versus radioembolization. Am J Transplant 9: 1920-1928, 2009.

10. Krishnan S, Dawson LA, Seong J, Akine Y, Beddar S, Briere TM, Crane $\mathrm{CH}$ and Mornex F: Radiotherapy for hepatocellular carcinoma: An overview. Ann Surg Oncol 15: 1015-1024, 2008.

11. Salem R, Lewandowski RJ, Mulcahy MF, Riaz A, Ryu RK, Ibrahim S, Atassi B, Baker T, Gates V, Miller FH, et al: Radioembolization for hepatocellular carcinoma using Yttrium-90 microspheres: A comprehensive report of long-term outcomes. Gastroenterology 138: 52-64, 2010.

12. Choi JW, Park JY, Ahn SH, Yoon KT, Ko HK, Lee DY, Lee JT, Kim KS, Choi JS, Han KH, et al: Efficacy and safety of transarterial chemoembolization in recurrent hepatocellular carcinoma after curative surgical resection. Am J Clin Oncol 32: 564-569, 2009.

13. Takayasu K, Arii S, Kudo M, Ichida T, Matsui O, Izumi N, Matsuyama Y, Sakamoto M, Nakashima O, Ku Y, et al: Superselective transarterial chemoembolization for hepatocellular carcinoma. Validation of treatment algorithm proposed by Japanese guidelines. J Hepatol 56: 886-892, 2012.

14. Lo CM, Ngan H, Tso WK, Liu CL, Lam CM, Poon RT, Fan ST and Wong J: Randomized controlled trial of transarterial lipiodol chemoembolization for unresectable hepatocellular carcinoma. Hepatology 35: 1164-1171, 2002.

15. Schwarz RE, Abou-Alfa GK, Geschwind JF, Krishnan S, Salem R and Venook AP; American Hepato-Pancreato-Biliary Association, Society of Surgical Oncology and Society for Surgery of the Alimentary Tract: Nonoperative therapies for combined modality treatment of hepatocellular cancer: Expert consensus statement. HPB (Oxford) 12: 313-320, 2010.

16. Zhong N, Li Y and Hua Y: Research progress of chinese medicine in the treatment of cancer pain. World Chin Med 8: 1501-1504, 2013.

17. Liu R, Runyon RS, Wang Y, Oliver SG, Fan T and Zhang W: Deciphering ancient combinatorial formulas: The Shexiang Baoxin pill. Science 347: S40-S42, 2015.

18. Choi HB: Knowledge transmission of medical prescription and the role of the literati officials from the Song dynasty: Focusing on huadupainongneibusan. Uisahak 27: 89-130, 2018.

19. Xu L and Cao Y: Native musk and synthetic musk ketone strongly induced the growth repression and the apoptosis of cancer cells BMC Complement Altern Med 16: 511, 2016.

20. Li Y, Zhang J and Li L: Comparison of the therapeutic effects of different compositions of muskone in the treatment of experimental myocardial infarct in rats and analgesia in mice. Phytother Res 22: 1219-1223, 2008.

21. Ma LF, Hao LP, Li LJ, Chen H and Ma JH: Process of the Study on Muscone. Hebei Chem Industry 33: 11-14, 2010 (In Chinese).

22. Guo Y, Gu H and Shi Z: Synthesis of 2,15-hexadecanedione as a precursor of muscone. Chin J Chem 23: 334-336, 2005.

23. Livak KJ and Schmittgen TD: Analysis of relative gene expression data using real-time quantitative PCR and the 2(-Delta Delta C(T)) method. Methods 25: 402-408, 2001.

24. Kuribayashi K, Mayes PA and El-Deiry WS: What are caspases 3 and 7 doing upstream of the mitochondria? Cancer Biol Ther 5: 763-765, 2006.

25. Lockshin RA: Programmed cell death: History and future of a concept. J Soc Biol 199: 169-173, 2005 (In French).

26. Visconti R and D'Adamio L: Functional cloning of genes regulating apoptosis in neuronal cells. Methods Mol Biol 399: 125-131, 2007.

27. Wu Y, Wang D, Wang X, Wang Y, Ren F, Chang D, Chang Z and Jia B: Caspase 3 is activated through caspase 8 instead of caspase 9 during H2O2-induced apoptosis in HeLa cells. Cell Physiol Biochem 27: 539-546, 2011.

28. Thornberry NA and Lazebnik Y: Caspases: Enemies within. Science 281: 1312-1316, 1998.

29. Vermeulen K, Berneman ZN and Van Bockstaele DR: Cell cycle and apoptosis. Cell Prolif 36: 165-175, 2003. 
30. Kim EH, Sohn S, Kwon HJ, Kim SU, Kim MJ, Lee SJ and Choi KS: Sodium selenite induces superoxide-mediated mitochondrial damage and subsequent autophagic cell death in malignant glioma cells. Cancer Res 67: 6314-6324, 2007.

31. Ueno T, Sato W, Horie Y, Komatsu M, Tanida I, Yoshida M, Ohshima S, Mak TW, Watanabe S and Kominami E: Loss of Pten, a tumor suppressor, causes the strong inhibition of autophagy without affecting LC3 lipidation. Autophagy 4: 692-700, 2008

32. Ohoka N, Yoshii S, Hattori T, Onozaki K and Hayashi H: TRB3, a novel ER stress-inducible gene, is induced via ATF4-CHOP pathway and is involved in cell death. EMBO J 24: 1243-1255, 2005.

33. Bromati CR, Lellis-Santos C, Yamanaka TS, Nogueira TCA, Leonelli M, Caperuto LC, Gorjão R, Leite AR, Anhê GF and Bordin S: UPR induces transient burst of apoptosis in islets of early lactating rats through reduced AKT phosphorylation via ATF4/CHOP stimulation of TRB3 expression. Am J Physiol Regul Integr Comp Physiol 300: R92-R 100, 2011.

34. Ye J and Koumenis C: ATF4, an ER stress and hypoxia-inducible transcription factor and its potential role in hypoxia tolerance and tumorigenesis. Curr Mol Med 9: 411-416, 2009.

35. Jiang S, Yan C, Fang QC, Shao ML, Zhang YL, Liu Y, Deng YP, Shan B, Liu JQ, Li HT, et al: Fibroblast growth factor 21 is regulated by the IRE1 $\alpha$-XBP1 branch of the unfolded protein response and counteracts endoplasmic reticulum stress-induced hepatic steatosis. J Biol Chem 289: 29751-29765, 2014.

36. Oyadomari S and Mori M: Roles of CHOP/GADD153 in endoplasmic reticulum stress. Cell Death Differ 11: 381-389, 2004.

37. Yamaguchi Y, Larkin D, Lara-Lemus R, Ramos-Castañeda J, Liu M and Arvan P: Endoplasmic reticulum (ER) chaperone regulation and survival of cells compensating for deficiency in the ER stress response kinase, PERK. J Biol Chem 283: 17020-17029, 2008.

38. Roidl D, Hellbach N, Bovio PP, Villarreal A, Heidrich S, Nestel S, Grüning BA, Boenisch U and Vogel T: DOT1L activity promotes proliferation and protects cortical neural stem cells from activation of ATF4-DDIT3-mediated ER stress in vitro. Stem Cells 34: 233-245, 2016.

39. Ma J, Yang YR, Chen W, Chen MH, Wang H, Wang XD, Sun LL, Wang FZ and Wang DC: Fluoxetine synergizes with temozolomide to induce the CHOP-dependent endoplasmic reticulum stress-related apoptosis pathway in glioma cells. Oncol Rep 36: 676-684, 2016

40. McCullough KD, Martindale JL, Klotz LO, Aw TY and Holbrook NJ: Gadd153 sensitizes cells to endoplasmic reticulum stress by down-regulating Bcl 2 and perturbing the cellular redox state. Mol Cell Biol 21: 1249-1259, 2001.

41. Sanli T, Steinberg GR, Singh G and Tsakiridis T: AMP-activated protein kinase (AMPK) beyond metabolism: A novel genomic stress sensor participating in the DNA damage response pathway. Cancer Biol Ther 15: 156-169, 2014.

42. Yu DC, Lee JS, Yoo JY, Shin H, Deng H, Wei Y and Yun CO: Soluble vascular endothelial growth factor decoy receptor FP3 exerts potent antiangiogenic effects. Mol Ther 20: 938-947, 2012.
43. Shao Y, Gao Z, Marks PA and Jiang X: Apoptotic and autophagic cell death induced by histone deacetylase inhibitors. Proc Natl Acad Sci USA 101: 18030-18035, 2004.

44. Kumar D, Shankar S and Srivastava RK: Rottlerin induces autophagy and apoptosis in prostate cancer stem cells via PI3K/Akt/mTOR signaling pathway. Cancer Lett 343: 179-189, 2014

45. Jing K, Song KS, Shin S, Kim N, Jeong S, Oh HR, Park JH, Seo KS, HeoJY,HanJ,etal:Docosahexaenoicacidinducesautophagythrough p53/AMPK/mTOR signaling and promotes apoptosis in human cancercells harboring wild-type p53. Autophagy 7: 1348-1358,2011.

46. Nguyen TM, Subramanian IV, Kelekar A and Ramakrishnan S: Kringle 5 of human plasminogen, an angiogenesis inhibitor, induces both autophagy and apoptotic death in endothelial cells. Blood 109: 4793-4802, 2007.

47. Baehrecke EH: Autophagy: Dual roles in life and death? Nat Rev Mol Cell Biol 6: 505-510, 2005

48. Levine B and Yuan J: Autophagy in cell death: An innocent convict? J Clin Invest 115: 2679-2688, 2005.

49. Kandala PK and Srivastava SK: Regulation of macroautophagy in ovarian cancer cells in vitro and in vivo by controlling glucose regulatory protein 78 and AMPK. Oncotarget 3: 435-449, 2012.

50. Shimizu S, Yoshida T, Tsujioka M and Arakawa S: Autophagic cell death and cancer. Int J Mol Sci 15: 3145-3153, 2014.

51. Yao X, Ma Y, Kang J, Wang Y, Jiang L, Chen M, Sha S, Sun X and Cao J: Perfluorooctane sulfonate induces autophagy-dependent apoptosis through spinster 1-mediated lysosomal-mitochondrial axis and impaired mitophagy. Toxicol Sci 153: 198-211, 2016

52. Wang Y, Liu Y, Liu X, Jiang L, Yang G, Sun X, Geng C, Li Q, Yao X and Chen M: Citreoviridin induces autophagy-dependent apoptosis through lysosomal-mitochondrial axis in human liver HepG2 cells. Toxins (Basel) 7: 3030-3044, 2015.

53. Sy LK, Yan SC, Lok CN, Man RY and Che CM: Timosaponin A-III induces autophagy preceding mitochondria-mediated apoptosis in HeLa cancer cells. Cancer Res 68: 10229-10237, 2008.

54. Qu X, Zou Z, Sun Q, Luby-Phelps K, Cheng P, Hogan RN, Gilpin C and Levine B: Autophagy gene-dependent clearance of apoptotic cells during embryonic development. Cell 128: 931-946, 2007.

55. Hu HJ, Shi ZY, Lin XL, Chen SM, Wang QY and Tang SY: Upregulation of Sestrin 2 expression protects against macrophage apoptosis induced by oxidized low-density lipoprotein. DNA Cell Biol 34: 296-302, 2015.

56. Budanov AV, Lee JH and Karin M: Stressin' Sestrins take an aging fight. EMBO Mol Med 2: 388-400, 2010.

57. Lee JH, Budanov AV and Karin M: Sestrins orchestrate cellular metabolism to attenuate aging. Cell Metab 18: 792-801, 2013.

58. Chen S, Yan W, Lang W, Yu J, Xu L, Xu X, Liu Y and Bao H: SESN2 correlates with advantageous prognosis in hepatocellular carcinoma. Diagn Pathol 12: 13-19, 2017.

(7) $\Theta$ This work is licensed under a Creative Commons Attribution-NonCommercial-NoDerivatives 4.0 International (CC BY-NC-ND 4.0) License. 